\title{
Prototyping a Dedicated Photovoltaic System Datalogger
}

\author{
Benabed Khadidja ${ }^{{ }^{1}}$, Boudghene Stambouli Amine ${ }^{1}$, Benabadji Noureddine ${ }^{2}$ \\ ${ }^{1}$ Department of Electronic, University of Sciences and Technologies of Oran (USTO-MB), Algeria \\ ${ }^{2}$ Department of Physics, LAAR Laboratory (USTO-MB), Algeria \\ *Corresponding author, e-mail: ben_khad@yahoo.fr
}

\begin{abstract}
Solar power is a renewable energy seen as one of the primary sources for electricity production in order to meet our daily needs. The conversion operation is sensitive and non-fault tolerant that can occur during operation of the system that affects its overall performance. We propose in this present paper a compact, low power and low-cost datalogger for the control and the monitoring based on a survey measure of five important physical parameters in the management and monitoring of the functioning of an electric system based on solar panels. These measures will be carried out at regular intervals, configurable through a PIC18F4520 microcontroller and stored in a large capacity memory type SD card.
\end{abstract}

Keywords: photovoltaic panels, datalogger, microcontroller 8-bit, SD card memory, micropower LDO regulator

Copyright $@ 2015$ Institute of Advanced Engineering and Science. All rights reserved.

\section{Introduction}

A datalogger is a device for measuring and storing a large amount of data. It is an allpurpose piece of measurement equipment that finds use in an extremely wide range of applications. Dataloggers have been successfully deployed in many scientific and industrial applications. Some of the important areas in which dataloggers are widely used include biomedical instrumentation [1], power quality measurement, automotive engineering [2], renewable energy [3], solar energy [4], Temperature and Humidity Analysis [5], solar irradiation [6], etc.

In this paper, we describe in detail the design and implementation of a compact and low cost automatic recording device (datalogger) to control and survey measures of several major physical parameters in the management and monitoring of the functioning of an electric system based on photovoltaic panels. It uses an 8-bit microcontroller (PIC18F4520) which deal with all the functions provided in the device (measuring, monitoring and recording). The major constraint of this datalogger is the autonomy of operation, consuming a functional power as low as possible (nanoWatt Technology) without affecting the accuracy of measurements and reliability of recorded data.

\section{Hardware Description}

The prototype device described in this paper is designed for $12 \mathrm{~V}$ photovoltaic panels system at a medium power (100 to $300 \mathrm{~W})$. It is responsible for performing automatic and periodic measurements of five important physical parameters to be monitored: the charging current of the energy accumulator ( $12 \mathrm{~V}$ battery), the discharge current, the charging voltage, the external temperature (of the $12 \mathrm{~V}$ P.V.) and the internal temperature (of the battery). These measurements are acquired periodically and immediately displayed on a $2 \times 16$ characters LCD display, where the first line is reserved to display the measured value of the voltage of the battery charge, the charging current (or discharge, depending on the sign) and the quantity of electricity (acquired or consumed), while the second line is reserved to display the clock, and, in turn, the number of the day, the internal temperature and the external temperature. A rudimentary but sufficient keyboard of three pushbuttons is used for the initial adjustment of the real time clock (RTC) of the device. The diagram in the figure 1 shows the main modules of this 
device: an 8-bit microcontroller (PIC18F4520), a 2x16 characters LCD display module, a tiny keyboard with 3 pushbuttons, the circuitry for four measurement channels (internal and external temperature, current and voltage), the regulated power supply section, and finally the mass storage SD memory.

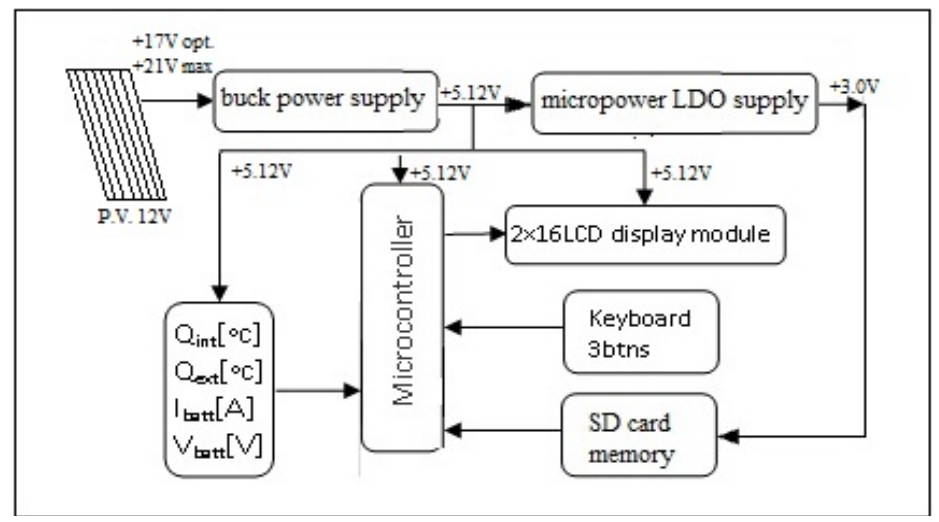

Figure 1. Block diagram of the prototype device.

\subsection{The 8-bit Microcontroller (PIC18F4520)}

It is a high-end microcontroller of the American society Microchip, which is now the world leader in this category of programmable digital components. It has a reduced instruction set computer (RISC) architecture, high speed performance and a large amount of flash memory; PICmicro are much better than other 8-bit microcontrollers using the old complex instruction computer (CISC) architecture (eg, Motorola 68705 or Intel 8051) [7]. It can be powered by a voltage from $1.8 \mathrm{~V}$ to $5.5 \mathrm{~V}$ [8]. Why do we have chosen $\mathrm{Vdd} 1=5.12 \mathrm{~V}$ ? With a resolution of 10-bit, the internal ADC picks up to 1024 measures, and with setting a voltage of $5.12 \mathrm{~V}$, we obtain a sensitivity of $5120 / 1024=5 \mathrm{mV}$ precisely. This step of $5 \mathrm{mV}$ is sufficient to measure the temperature detected by the LM35 series temperature sensors, which provide a step of $10 \mathrm{mV}$ per degree Celsius, and an accuracy of $0.5^{\circ} \mathrm{C}$. Finally, the PIC18F4520 is clocked by an $8 \mathrm{MHz}$ system internal clock (giving a $1 / 2 \mu$ s per instruction, except for jump instructions that require $1 \mu \mathrm{s})$, and an external quartz of $32768 \mathrm{~Hz}$ to accurately manage the real time clock and calendar (RTCC), with the internal 16-bit Timer1 (Figure 2). The PIC18F4520 consumes a current about $3.5 \mathrm{~mA}$ in run time mode (at $8 \mathrm{MHz}$ ), but this value drops down to 9 $\mu \mathrm{A}$ in sleep mode (PIC halted, except for timer1 internal clock at $32768 \mathrm{~Hz}$ ).

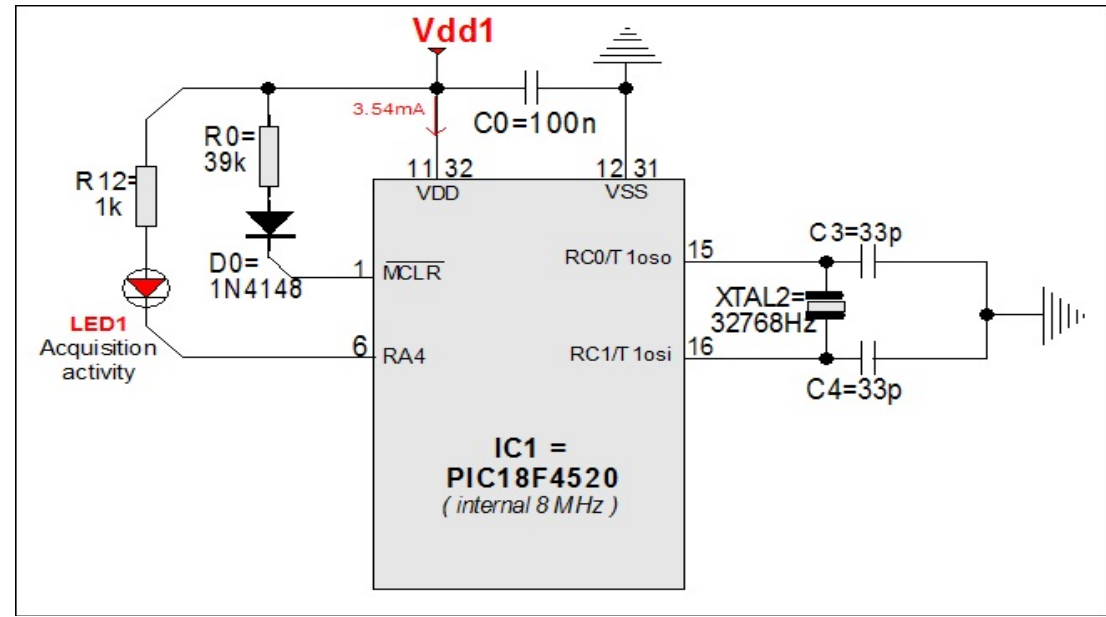

Figure 2. The PIC18F4520 circuit with its two quartz $(8 \mathrm{MHz}$ and $32768 \mathrm{~Hz})$ 


\subsection{The $2 \times 16$ Characters LCD Display Module}

The $2 \times 16$ characters LCD module requires a minimum of 10 lines I/O (input / output) to connect to the PIC, in 8-bit mode, or only $6 \mathrm{I} / \mathrm{O}$ lines, in 4-bit mode. This latter method was therefore chosen to minimize the number of lines I/O (Figure 3). The command line (EN: pin 6) of the LCD display is driven directly by the output RB3 (pin 36) of PIC18F4520, while the command line (RS: pin 4) of the LCD is driven by the RB2 output (pin 35) [9]. In order to minimize the global current consumption in sleep mode, we have to avoid to power permanently the LCD display. Hence, pin 2 (Vdd) and pin 15 (backlight) of the LCD display are not directly connected to the primary power supply, but rather to an output pin of the PICmicro (pin 13). The same idea has been applied for the temperature sensor which is powered only during the time of analog acquisition.

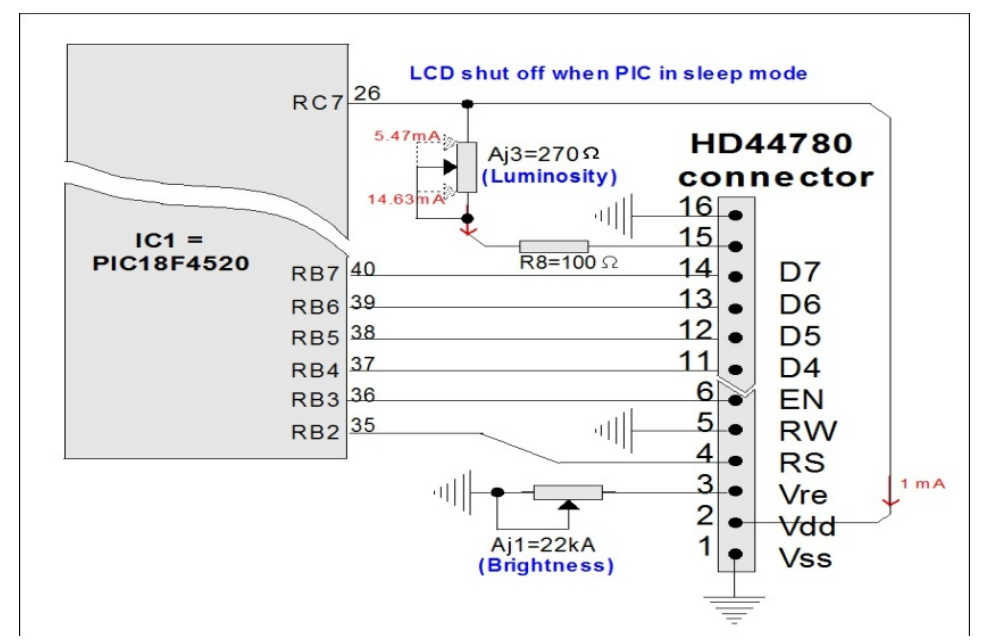

Figure 3. The 2x16 LCD display module 4-bit mode

\subsection{The Three Buttons Keyboard}

The keyboard has three pushbuttons driven with only two I/O (Figure 4); pushbuttons BP1 and BP2 are directly connected to input pins RB0 and RB1 (with their internal pullup resistors activated, only during the keyboard polling time) and are used to increment or decrement of the RTCC, whereas pushbutton BP3, indirectly connected to RBO and RB1 simultaneously, through diodes D1 and D2, is used to roll over hour, minute, second, day, month and year. When the PICmicro is put in sleep mode, the LCD module is shut off (its supply is controlled through pin RC7) and can be powered again by pushbutton BP3.

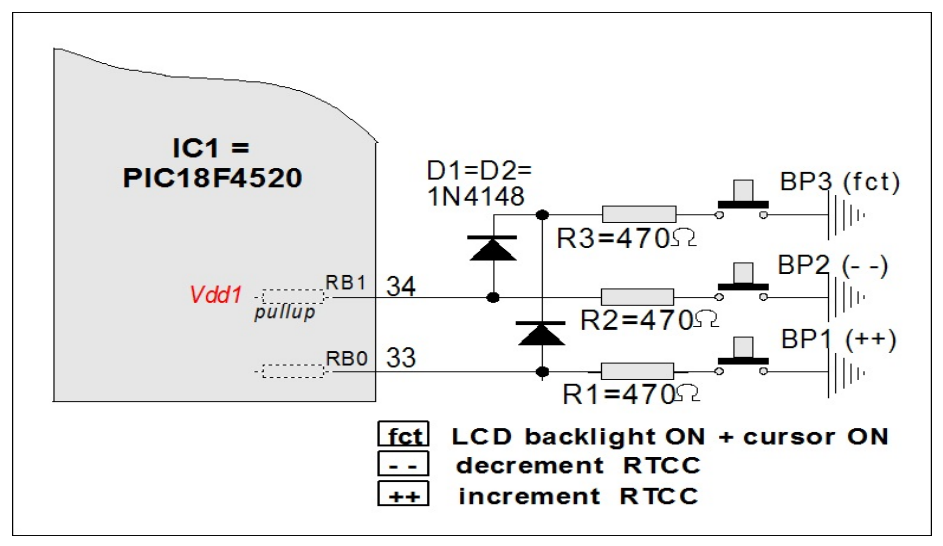

Figure 4. The three push buttons keyboard 


\subsection{The Circuitry for Four Measurement Channels}

Only four of the PIC18F4520 analog inputs have been devoted to measure five important physical parameters (Figure 5): the charging current (Ibat positive) for the energy storage pack ( $12 \mathrm{~V}$ battery), the discharge current (Ibat negative), the charging voltage (Vbat), the external temperature $\left(T^{\circ} \mathrm{ext}\right.$, of the photovoltaic panels) and the internal temperature $\left(T^{\circ} \mathrm{int}\right.$, of the battery). The LM35CZ and LM335 temperature sensors are used, with a sensitivity of 10 $\mathrm{mV} /{ }^{\circ} \mathrm{C}$ and an accuracy of $0.5^{\circ} \mathrm{C}$ and $1{ }^{\circ} \mathrm{C}$ respectively. The temperature range is $-40{ }^{\circ} \mathrm{C}$ to 110 ${ }^{\circ} \mathrm{C}$ for the first sensor, and $-40^{\circ} \mathrm{C}$ to $100^{\circ} \mathrm{C}$ for the second one. They can be powered by a DC voltage from $4 \mathrm{~V}$ to $20 \mathrm{~V}$ [10]. The charging current (and discharge) of the battery is done by measuring a voltage drop across a low resistance $(0.1 \mathrm{ohm})$ in series with the positive terminal of the battery to be recharged. The calculation of the maximum power dissipated by that resistance depends on the maximum current that can be sourced by the solar panels in use, and the maximum current allowed for user consumption. The charging voltage to be measured is taken from a conventional voltage divider, decoupled with capacitors C12 and C13 used to filter any transient voltage or noise that could be induced through long leads from the solar panels.

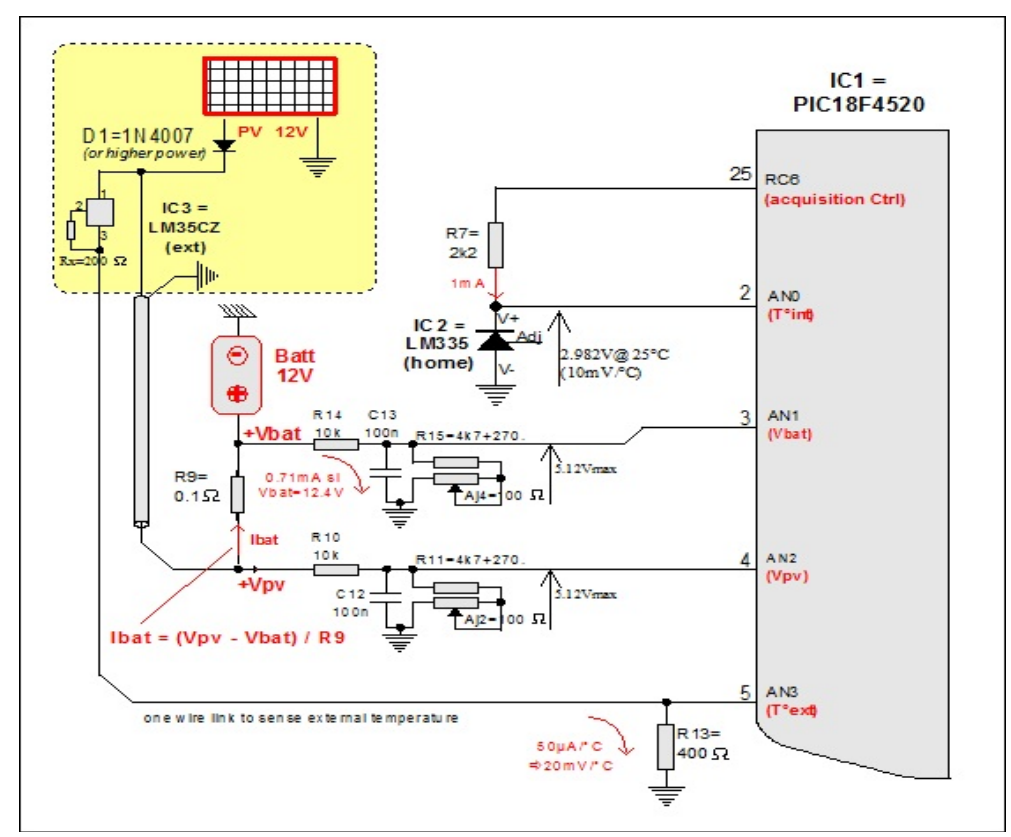

Figure 5. Circuitry for 4 analog channels

\subsection{The Power Supplies}

Two power supplies have been designed: One delivering a stable $5.12 \mathrm{Vdc}$ for the microcontroller, the LCD display and active temperature sensors, and one delivering a stable $3.0 \mathrm{Vdc}$ for the SD card memory. As with any portable embedded design, both high conversion efficiency and very low standby power dissipation were among our primary goals. The primary power supply unit (Figure 6) must deal with a wide input range (10.5V to $21 \mathrm{~V}$ ), we choose a step-down dedicated integrated circuit: the MCP16311 [11] characterized with efficiency up to $96 \%$ and a very low quiescent current (44 $\mu \mathrm{A}$ typical). The secondary power supply unit (figure 7 ) is based on a micropower LDO linear regulator, the MCP1702 characterized with low drop out of $100 \mathrm{mV} @ 40 \mathrm{~mA}$, and an ultra low quiescent current (2 $\mu \mathrm{A}$ typical). These two integrated circuits offer robust operation with integrated over-current protection, short-circuit protection, high-temperature operation capabilities, and over-temperature protection features. The SD card memory is periodically activated (each hour) only to save measures, then it is completely shut off (to save power), hence the use of the P channel mosfet T1 driven with the output pin RA6 of the PICmicro. 


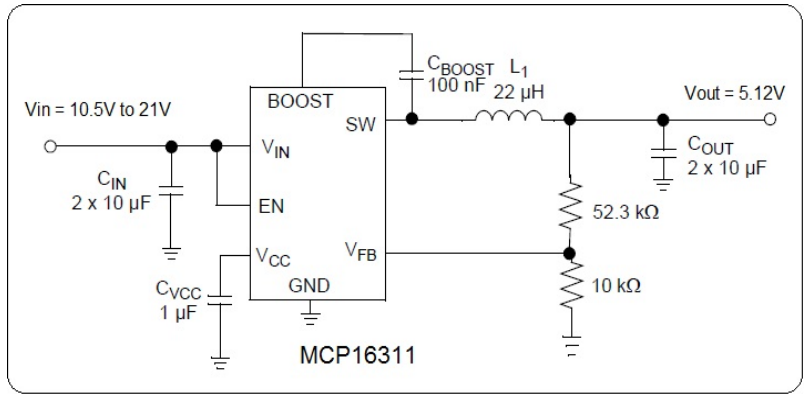

Figure 6. The primary power supply unit

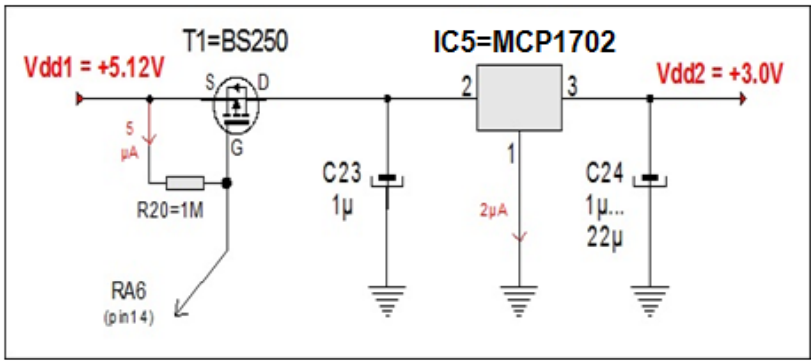

Figure 7. The power supply for the SD card memory

\subsection{The Memory SD Card (2 GO)}

The memory used in this device consists of a SD card of 2 GB for daily recording of various parameters acquired periodically. The Table 1 summarizes the format of the measured data over one year.

The SD memory card is configured in the FAT16 file system from Microsoft. We used MikroC compiler (of Mikroelektronica) which has standard built in routines for SD memory. Each day, a file is saved under the name LOG_Nxxx.DAT ( $x x x$ is the number of days, ranging from 001 to 365 or 366, if leap year), in binary format, with a fixed size of 27 bytes. The Figure 8 details the interconnection of the SD card memory with the PIC18F4520 microcontroller. The secondary regulated power supply delivering $3.0 \mathrm{Vdc}$ was designed only for the SD card memory [12], that accepts a rather narrow voltage margin (between $2.7 \mathrm{~V}$ and $3.6 \mathrm{~V}$ only). The SD card memory is very sensitive to peak voltage variations on its supply pins (Vdd, Vss), hence the need for the two decoupling capacitors C30 and C31 close to the SD. The inputs/outputs of PIC work with logic levels (0V, 5V) and must be adapted to SD logic levels (OV, 3V), with the resistive voltage divider (R30 to R35). Finally, the red LED is optional and serves only for activity (write/read) control of the SD memory card.

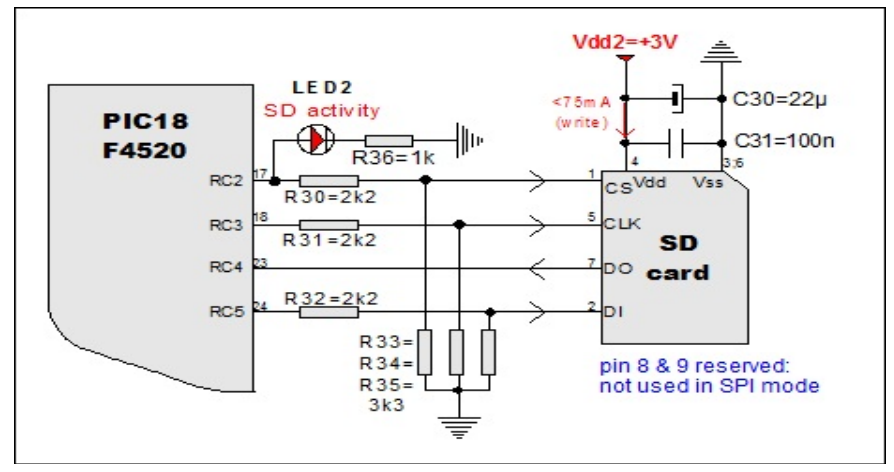

Figure 8. The memory SD card (2 GO)

TELKOMNIKA Vol. 16, No. 3, December 2015 : 488 - 494 
Table 1: Recording format of a package of measures for one day (size $=27$ bytes)

\begin{tabular}{lll}
\hline Nbr bytes & Variables & Meaning \\
\hline 3 & nDay & Number of days in one year $=1,2, \ldots, 365$ (or \\
2 & Year & 366 ) \\
6 & Qday & Year $=00,01, \ldots, 99$ correspond to 2000 to \\
2 & RhoMax & 2099 \\
2 & TintMax & Quantity of electricity accumulated in one day \\
2 & TextMax & Maximum efficiency in one day \\
6 & Qnight & Maximum internal temperature \\
2 & TintMin & Maximum external temperature \\
2 & TextMin & Quantity of electricity consumed at night \\
& & Minimum internal temperature \\
& & Minimum external temperature \\
\hline
\end{tabular}

\section{Results and discussion}

Unlike another datalogger, also built in our laboratory, but based on the microcontroller PIC16F716 [13], our prototype is based on the microcontroller PIC18F4520 which has several enhancements:

1) It has the ability to accept a greater number of input channels, and it is provided with an internal $A D C$ with higher acquisition speed and resolution.

2) The external memory is based on a high capacity SD card of 2GB for daily recording of various parameters.

3) Our prototype uses a power supply based on dedicated I.C. for portable devices (efficiency up to $96 \%$, and quiescent current of $44 \mu \mathrm{A}$ typical) whereas in [13], the regulated power supply comprises a classic integrated regulator $78 \mathrm{~L} 05$ characterized with a quiescent current of $4 \mathrm{~mA}$ !

\section{Conclusion}

This paper describes the design and implementation of an automatic recording device (datalogger) to measure several important physical parameters (internal and external temperature, the current and voltage of the battery). This prototype is recommended in the management and the monitoring of an operational solar power plant based on photovoltaic panels. The design was focused principally with power consumption in mind, and a special care was given when choosing the right components for this purpose (step-down integrated regulator with very low quiescent current, micropower LDO regulator, nanoWatt microcontroller, low power sensors, and a very small ratio run-time/standby mode). The modular conception applied in the hardware of this embedded design has been also applied in the development of the dedicated firmware in a high level language, where interrupts have been used for each separate task: analog acquisition, keyboard sensing, LCD display.

\section{References}

[1] Akingbade KF, Alimi IA, Oni T. Design of a Data Logger for Biomedical Signals. International Journal of Electronics and Electrical Engineering (IJEEE). 2015; 3(2): 149-152.

[2] Holland E. Formula-SAE Wireless Data Logger. Journal of Undergraduate Research at Minnesota State University. 2002: 3.

[3] Srinonchat J. Improvement of a data logger system for renewable energy. Asian Journal on Energy and Environment. 2009; 10(3): 142-148.

[4] Akposionu S. Design and Fabrication of A Low-Cost Data Logger for Solar Energy Parameters. Journal of Energy Technologies and Policy. 2012; 2(6): 12-17.

[5] Waghmare MB, Chatu S. Temperature and Humidity Analysis using Data Logger of Data Acquisition System. International Journal of Emerging Technology and Advanced Engineering. 2012; 2(1): $102-$ 106.

[6] Beni RA, Perangin-angin HP, Pebriyanti G. Implementation of ATMega8 Microcontroller for Data Logger of Solar Irradiation. International Journal of Applied Mathematics and Modeling (IJA2M). 2015; 3(1): 1-8.

[7] Dogan I. Design of a microcontroller based multichannel temperature data logger device with SD card storage and real time clock interface. Electronics World. 2009: 26-32. 
[8] Sarker S, Chakraborty M, Banerjee A. Low Cost Embedded System/Android Based Smart Home Automation System Using Wireless Networking. International Journal of Electronics and Communication Engineering. 2014; 7(2): 175-186.

[9] Sethumadhavan S. Smart Metering and Home Automation Solutions for Next Decade Using Zigbee Technology. SSRG International Journal of Electronics and Communication Engineering (SSRGIJECE). 2015; 2(6): 32-42.

[10] Marimuthul R, Deepak V, Gowtham S, Ram PV. Remote Heart Rate Monitoring System. International Journal of Electronics and Communication Engineering Research (IJECER). 2013; 1(3): 47-52.

[11] Daison SS, Vinoth KK, Suresh KS. High Efficient Module of Boost Converter in PV Module. International Journal of Electrical and Computer Engineering (IJECE). 2012; 2(6): 758-781.

[12] Reddy BNK, Venktram N, Sireesha. An Efficient Data Transmission by using Modern USB Flash. International Journal of Electrical and Computer Engineering (IJECE). 2014; 4(5): 730-740.

[13] Naim H, Hassini A, Benabadji N, Falil FZ, Bouadi A. Realization of an Inexpensive Embedded MiniDatalogger for Measuring and Controlling Photovoltaic System. Journal of Solar Energy Engineering. 2015; 137(2): 5.

TELKOMNIKA Vol. 16, No. 3, December 2015 : 488 - 494 